\title{
¿ES POSIBLE CONSTRUIR UNA TEORÍA DE LA JUSTICIA FEMINISTA?
}

\section{IS IT POSSIBLE TO CREATE A FEMINIST THEORY OF JUSTICE?}

\section{María Isabel Puente Gallegos}

Universidad de Valencia, Valencia, España

mapuenga@gmail.com

https://orcid.org/0000-0002-4949-211X

Resumen: Aunque existe una coordinación social, formal y coercitiva que exige la observancia de la ley, en el sistema de impartición de justicia frecuentemente puede apreciarse la exégesis androcéntrica de los juzgadores. Este sistema normativo creado, aplicado e interpretado desde la masculinidad tradicional, categoriza por medio del derecho a las buenas mujeres dentro de la ley, y malas mujeres fuera de la ley. El objetivo de la presente reflexión consiste en prefigurar pautas para reivindicar la dignidad de las mujeres en el acceso a la justicia como sujetos marginados por la heteroaplicatividad de la norma patriarcal. El aspecto metodológico de la presente investigación es de corte cualitativo estrictamente documental. Entre los hallazgos principales de la presente, se encuentra que el feminismo es una configuración efectiva de teoría de la justicia que responde a las necesidades de las mujeres acorde a sus contextos sociales, y que, además, esta praxis no puede ajustarse a una única teoría universalista de justicia ya que no existe una unívoca categoría de mujer. Esto a su vez implica que, las mujeres tengan la prerrogativa a presentar el derecho a ser malas mujeres.

Abstract: Although there is a social, formal and coercive coordination that requires the observance of the law, in the system of administration of justice the androcentric exegesis of the judges can often be appreciated. This normative system created, applied and interpreted from the traditional masculinity, categorizes by means of the right good women within the law, and bad women outside the law. The objective of this reflection is to prefigure guidelines to vindicate the dignity of women in access to justice as marginalized subjects due to the hetero-applicability of the patriarchal norm. The methodological aspect of this research is of a strictly documentary qualitative nature. Among the main findings of the present, it is found that feminism is an effective 
configuration of the theory of justice that responds to the needs of women according to their social contexts, and that furthermore, this action cannot be adjusted to a single universalist theory. of justice since there is no unambiguous category of woman. This in turn implies that, women have the prerogative to present the right to be bad women.

Financiamiento: La presente investigación fue financiada por el Gobierno del Estado de Guanajuato, México, a través del Instituto de Financiamiento e Información para la Educación como parte del programa de Beca Talentos.

Conflicto de intereses: La autora declara que no existen conflicto de interés. Los financiadores no han tenido ningún rol en: el diseño del estudio; la recolección, análisis o interpretación de los datos; en la escritura del manuscrito, o en la decisión de publicar los resultados.

\section{Introducción}

A lo largo de la historia del derecho, se han configurado corrientes, conceptos y teorías de la justicia. Desde el código de Hammurabi y los filósofos de la Grecia antigua se aparecen diversas ontologías de la justicia. Celso afirmaba que la justicia consiste en dar a cada uno lo que le corresponde, mientras que Sócrates aseveraba que la justicia es el conocimiento de lo útil y lo bueno. Por otro lado, Trasímaco y Calicles señalaban desde una postura metaética que la justicia no es otra cosa más que lo que le conviene al más fuerte. Por último, Aristóteles dividía a la justicia en universal, como la suma de virtudes sociales, y en particular, cuando esta impide la generación de desigualdades. Así a lo largo de la tradición iusfilosófica, autores de teorías de la justicia como Rawls, Sen, Marx o Van Paris han tenido críticas feministas a sus teorías, de los principales señalamientos se advierte que principalmente sus puntos de vista excluyeron la experiencia femenina, o el género. Aunque también existieron sus excepciones como John Stuart Mill, quien mostró especial interés en la búsqueda de igualdad entre sexos. Dicho teórico afirmaba que en general lo masculino no tolera la idea de vivir en igualdad, y su trabajo ha sido excepcional en el campo de la filosofía ya que usualmente los varones no consideraron la libertad y emancipación femeninas en búsqueda de paridad (Camps, 2020: 105). Este anhelo de generalidad busca formar conceptos universalistas de justicia que sean aplicables a experiencias particulares, constituyendo un dilema inextricable para las mujeres y el derecho. Así pues, definir lo que es justo para la sociedad ha concatenado un diálogo intersubjetivo infinito. Entonces, lo justo para las mujeres, se vuelve una categoría que no tiene una ontología unívoca ni en la filosofía ni en el derecho.

Partiendo de la tesis de que el género influye en todas las concepciones del conocimiento, desde la perspectiva de la persona que conoce, así como las prácticas de investigación, es imprescindible tener identificadas las concepciones dominantes en las prácticas de adquisición y justificación del conocimiento que sistemáticamente ponen en desventaja a las mujeres porque frecuentemente se les descarta de la investigación, y por ende les es negada la autoridad epistémica (Blázquez, 2012: 22). En los procesos de creación, aplicación, interpretación y edu- 
cación jurídica frecuentemente mancillan los modos cognitivos femeninos de conocimiento. Dichas relaciones desiguales de poder refuerzan y reproducen jerarquías de género, entonces, si la ciencia no es ni objetiva, ni neutra, ni universal, ¿por qué la ciencia jurídica sería la excepción?

La división sexual como estructura fundamental del sistema de género, que tiene entre sus elementos centrales en el sometimiento del cuerpo femenino, por medio del cual subyace un conflicto de poder ejercido sobre la capacidad reproductiva de las mujeres es una de las claves desde donde se origina la subordinación-dominación entre los géneros (Rubin, 1975: 166). Esta subordinación que afecta a las mujeres no es estrictamente una cuestión biológica, sino muchas veces, una cuestión de poder que no se ubica exclusivamente en el Estado, sino que se trata de un poder múltiple localizado en diversos espacios sociales como los legales (Barbieri, 1992: 148).

Si bien, las mujeres han sido definidas y caracterizadas desde la mirada masculina, desde todos los campos del conocimiento incluyendo el derecho, donde la categoría mujer está interpretada como inferior a la del hombre, por lo que se omiten a las mujeres de los estudios en la ciencia, siendo lo masculino sinónimo de lo universal, que tienen como consecuencia la creación de relaciones de poder en formas de identidad precedidas por el sexo (Schiebinger, 1991: 379). Esta voluntad de transformar algo que no conocemos, en este caso, las mujeres, en algo que todavía conocemos menos, como la justicia, pone en serios problemas al acceso a la justicia para las mujeres a través del sistema jurídico (Castoriadis, 1987: 72).

Las mujeres comprendidas desde una perspectiva androcéntrica, como lo ines- cencial frente a lo esencial, sólo han tenido lo que los hombres han querido cederles. Por lo que, a partir de la diferencia sexual, en el derecho, se jerarquiza la dignidad de los destinatarios de la norma y las mujeres como lo otro (Beauvoir, 1981: 4). Así pues, el androcentrismo jurídico ha situado categóricamente al hombre como el centro de la ley, la medida de lo justo y como universal de lo humano (Costa, 2017: 2). Para muchas personas, la ley es como visitar un país extranjero, con idiomas ininteligibles, trampas secretas, dogmas rígidos y rituales draconianos que tienen consecuencias tan intimidantes como incomprensibles. No obstante, muchas mujeres sienten que no hay nada para ellas en los contenidos de la ley, ya que no se sienten identificadas con las expectativas de estas, vertidos en los cuerpos normativos (Mackinnon, 2007: 32-33). Esta instauración del derecho es sin duda la instauración de poder, y por lo tanto es un acto de manifestación inmediata de violencia (Benjamin, 1998: 24).

Este androcentrismo jurídico como sistema estructural y sistemáticamente violento para las mujeres no es estático, y si bien, tiene dinámicas cambiantes, también los feminismos representan una propuesta de liberación y reivindicación de la dignidad de las mujeres. Esto puede evidenciarse en las olas del feminismo, donde gradualmente las demandas por emancipación, igualdad y libertad serían eventualmente reconocidas por las sociedades patriarcales y vertidas en los ordenamientos legales, como lo han sido el derecho al voto, el derecho a la educación, derecho a la interrupción legal del embarazo, derecho a recibir la misma paga por igual trabajo, etc.) (Varela, 2014: 2020).

La hipótesis que se plantea es que el feminismo constituye una teoría de la 
justicia para las mujeres que se edifica con la ley, sin la ley y a pesar de la ley. Adicionalmente, la presente reflexión no tiene como finalidad crear una ontología de la justicia feminista, por lo que no trata de interpretar qué es lo que debería ser lo justo para las mujeres desde la fenomenología jurídica tradicional; sino que lo que busca es generar bases para que ellas puedan ejercer su prerrogativa al derecho a ser malas mujeres.

\section{Métodos}

El aspecto metodológico de la presente investigación es de corte cualitativo estrictamente documental. Su naturaleza es descriptiva, analítica y comparativa en relación con el binomio de procesos sociales y legales, en el cual se incluyen epistemologías jurídicas, filosóficas y feministas.

Siguiendo a Sandra Harding, en este estudio no se pretende construir sobre el conocimiento iusfilosófico preexistente, ya que dicho tiene rasgos estructurales, sistemáticos, jerárquicos y dicotómicos que originalmente excluyeron a las mujeres. Lo que aquí se pretende es considerar las experiencias jurídicas de las mujeres, a fin de explicar al feminismo como un sinónimo de teoría de la justicia para las mujeres (Harding, 1998). Por ello, la epistemología y hermenéutica contenidas en la presente son netamente feministas.

Adicionalmente, Eli Bartra puntualiza que la investigación feminista tiene un objeto de estudio particular que son las mujeres, sin embargo, para ella, una investigación no sexista puede realizarse sobre cualquier objeto de estudio (contaminación, transporte, artes) mientras precisamente evite los errores sexistas (Bartra, 2012: 69). Por lo anterior, es necesario precisar que a diferencia de los estudios no sexistas y feministas, es que si bien, ambos centran su mirada en la importancia y diferencias que nacen por motivos del sistema sexogénero, en los estudios feministas, además de considerar las relaciones de dicho sistema, se tiene la finalidad de mejorar la condición de las mujeres (Eichler, 1997: 12). La estructura de la presente constará de: introducción, metodología, resultados, conclusiones y referencias.

\section{Resultados}

Si desde el principio se afirmaba que no existe un consenso unívoco de justicia, incluso si la concepción perfecta de la justicia ya existiera, el problema ahora se convertiría en ¿Cómo lograr fines justos a través de medios legítimos? Por lo que una puede entonces buscar una teoría feminista de la justicia como base desde la cual generar propuestas para erradicar las injusticias de género (Putnam, 1995: 298). Por otra parte, el concepto de teoría es definido como "el conjunto ordenado y organizado de proposiciones, relaciones y demostraciones, con que se da una explicación acerca de cierto objeto" (DEM, 2021). En este caso si vamos a hablar de una teoría feminista de la justicia se debe considerar lo justo desde dicho conjunto organizado de proposiciones, relaciones y denostaciones desde una perspectiva que reivindique la dignidad de las mujeres.

Frecuentemente en los ordenamientos jurídicos la justicia figura como un mandato, irrenunciable, imprescriptible e inalienable e imparcial al que toda persona puede acudir, tal como el caso de la Declaración Universal de los Derechos Humanos (ONU, 1948), la cual en su artículo décimo a la letra reza que: 
Toda persona tiene derecho, en condiciones de plena igualdad, a ser oída públicamente y con justicia por un tribunal independiente e imparcial, para la determinación de sus derechos y obligaciones o para el examen de cualquier acusación contra ella en materia penal.

Si bien, las leyes pueden proclamar la igualdad, los derechos y libertades, de forma inalienable, imprescriptible e irrenunciable, es pertinente considerar que las desigualdades, injusticias y opresiones no se erradican por decreto legislativo, este fetichismo jurídico al que refieren autores como Antonio Salamanca Serrano, definen como un objeto al que enajenadamente se le atribuye la fuerza de un poder que no tiene y se le consagra obediencia. Los derechos no son entonces, sino puro texto. Se les pronuncia e invoca y no producen nada (Serrano, 2017: 325). El problema de este formalismo normativista positivista es el horizonte jurídico hegemónico en Iberoamérica, que se extiende en todas las ramas del derecho, y por ello es necesario revisar desde las teorías críticas del derecho y los feminismos los efectos de las leyes, a fin de generar normativa que genere relaciones más simétricas de poder.

Desde una postura crítica al derecho penal moderno, el derecho positivo vigente privilegia la tutela el honor femenino porque este es el honor creado desde una subjetivación procedente de la masculinidad tradicional. O sea que el bien jurídico a tutelar en los tipos penales, es en realidad el honor masculino que se convierte en una carga para las mujeres. Por ello, puede afirmarse que existe un sistema punitivo el cual se define a la Mujer desde un criterio masculino, mediante el cual la ley penal es la escritura de una ideología en la que se ubica a las mujeres en un lugar y en una relación definida desde fuera de ellas mismas (Núñez, 2021: 102).
Respecto a lo anterior, se estima que las mujeres, a diferencia de los sentenciados varones, son condenadas a una media de cinco años más de prisión por la comisión de los mismos delitos, lo cual implica un doble castigo, primero por la comisión de un hecho delictivo, y la segunda determinada por factores asociados al género (Reinserta, 2020: 66). En esta misma materia, concurre una revictimización de las mujeres basada en estereotipos de género, como el sentir que no se les va a creer, que fue su culpa o que no es tan grave la violencia que han sufrido, las cuales se convierten en abstenciones para denunciar delitos (Carranco, 2020: 33).

En la actividad jurisdiccional, los estereotipos de género se vuelven un condicionamiento muchas veces invisible, en el acceso a la justicia para las mujeres. Ello generalmente queda supeditado al cumplimiento del arquetipo de buena o mala mujer. Si bien, es común que los estereotipos pasen desapercibidos o que, incluso cuando se logra advertirlos, existe la tendencia a justificarles, por lo que es imperativo estar pendientes de su presencia y generar acciones afirmativas y metodologías jurisdiccionales para juzgar sin estereotipos (SCJN, 2020: 63).

Incluso la patriarcalización de la justicia puede ser revisada desde el lenguaje, pues frecuentemente se incurre en sexismo lingüístico cuando un lenguaje resulta discriminatorio por la forma, pues esto afecta también a su contenido. Es decir, que cuando en un discurso, un texto o un mensaje jurídico se emplean estructuras o palabras que ocultan o discriminan a alguno de los sexos, esto vulnera el principio de igualdad (Castro y Bodelón, 2013: 4).

Esta imparcialidad está aún lejos de aterrizar en muchos tribunales. En principio 
porque la ciencia jurídica no es ni universal, ni objetiva, ni imparcial, especialmente frente al género. Este sistema sexo-género reflejado en la ley, influye en que las mujeres, performen las características de una buena mujer desde la mirada masculina su acceso a la justicia patriarcal. Por ejemplo, la organización Womens Link Worldwide (WLW, 2021) tiene un concurso anual para denunciar las sentencias más misóginas alrededor del mundo. Algunos de los fallos galardonados se mencionan a continuación:

En Argentina, un pastor evangélico de 59 años había sido condenado por la violación de dos menores de edad. No obstante, en la apelación de la sentencia, su pena le fue reducida a la mitad bajo el argumento de que las víctimas, por su pertenencia étnico-cultural, se consideraba normal que desde temprana edad sostuvieran relaciones sexuales (WLW, 2010). En Afganistán una mujer fue condenada a doce años de cárcel por el delito de adulterio tras haber sido violada por su primo. Le fue ofrecida la conmutación de la pena para compurgarla en libertad, condicionándola a cambio de contraer matrimonio con su agresor (WLW, 2012). En Reino Unido un juzgador exculpó a un reconocido millonario por la violación de una mujer. El argumento de la defensa constituía que el hombre había penetrado a la mujer de manera fortuita al tropezar y caer accidentalmente sobre ella (WLW, 2016). En Brasil un juez penal rechazó radicar numerosas denuncias por violencia intrafamiliar, calificando aquel tipo penal como absurdo y diabólico, su argumento literalmente fue que "el mundo es masculino, dios es masculino, Jesús fue hombre y la mujer es culpable de la desgracia de la humanidad" (WLW, 2010). En España una jueza le negó medidas de protección a una víctima de diversos tipos de violencia, incluida la sexual. La jueza en su interrogatorio no le creyó a la víctima que hubiera cerrado bien las piernas para evitar su violación (WLW, 2016). Por último, la Corte Constitucional de Colombia ratificó un fallo que consistía en hacer pasar a una convicta por aislamiento por treinta días en un calabozo sin ventanas y con derecho a sólo dos horas diarias de sol, ello tras haber sido sorprendida besándose con otra reclusa (WLW, 2010).

Si bien, se han realizado múltiples esfuerzos para erradicar las anteriores desigualdades, entre ellas el ejercicio del mainstreaming de género, que tiene entre sus finalidades el justificar su aplicación a fin de conseguir igualdad efectiva entre mujeres y varones, generando un cambio cultural que sea beneficioso para la sociedad en su conjunto (Fernández, 2015: 335). A pesar de ello, y desde su creación en Beijing 95, dicha práctica en la ley ha ayudado a alcanzar una igualdad legal paulatina, ya que la aplicación de dicha práctica sólo ha logrado ayudar a las mujeres a adaptarse a un sistema opresivo, en lugar de politizar a las usuarias, y hacerlas conscientes de su opresión.

De lo anterior se desprenden distintas categorías de mujeres a las que Marcela Lagarde (2016) define como cautiverios, que son las opresiones sociales que buscan mantener un status quo que penaliza a las mujeres que subvierten de las categorías que no se cuestionan desde el establishment, tales como la clase social, factores religiosos, las relaciones desiguales de poder, blancura y blanquitud, tener una preferencia sexual enmarcada en la diversidad (Lagarde, 2016).

Si bien, es imperativo que existan más mujeres en cargos de poder en las distintas 
áreas del sistema normativo, aún subsiste una distribución desproporcional entre puestos de poder en las Cortes mexicanas entre varones y mujeres. Adicionalmente, las unidades de igualdad institucionales, que en teoría podrían ayudar a corregir la exégesis androcéntrica de los centros de impartición de justicia, en realidad cuentan con facultades limitadas en sus organizaciones, además, no ostentan algún grado de poder y en el peor de los casos solo han servido para reproducir estereotipos de género (Vela, 2017: 147).

Pasando a otra área jurídica, en materia laboral también se ve reflejado el sexismo jurídico, pues aún no se ha podido combatir la brecha salarial a nivel mundial. Las mujeres continúan ganando menos dinero que los hombres por realizar los mismos trabajos (Arceo-Gómez, 2014: 627), la discriminación en la contratación hacia las mujeres casadas sobre las solteras es persistente, y el techo de cristal continúa sin agrietarse en los cargos de mayor responsabilidad y remuneración entre varones y mujeres (Sarrió y otros, 2002: Horbath 2014). Aunado a esto, menos del $5 \%$ en de las personas que inician un litigio por discriminación en el empleo obtienen algún tipo de reparación judicial en los Estados Unidos. Ello es debido a que, en la mayoría de los casos, los juzgadores se rehúsan a atribuir los resultados de un evento discriminatorio. Lo más común es que se lo atribuyan a una falla de capacidad de la persona excluida y no a discriminación por sexo o género (Eyer, 2011: 1304).

Otra actual lucha feminista en el derecho ha sido la dignificación de los trabajos de cuidado, ya que la sociedad patriarcal los ha considerado un atributo natural y forzosamente subordinado en vez de ser reconocido como trabajo remunerado, el cual además debe hacerles sentir plenas a las mujeres para desempeñar dicho trabajo sin obtener un salario a cambio (Federici, 2013: 37). Dichas tareas, determinadas por imperativos culturales hacen responsables a las mujeres del bienestar de su grupo, ello ha traído como consecuencia negativa el hecho de que ser amas de casa sea un sinónimo de pobreza (Deschamps, 2020). Es imperativo que los operadores jurídicos comprendan que cada persona es un fin en sí misma y que ninguna constituye un simple medio para los objetos o fines de otras. No se juzgaría apropiado tratar a los varones como ciudadanos y a las mujeres como meras asistentes de ellos (Nussbaum, 2014: 147).

A manera de ejemplo, el feminismo como teoría de justicia para las mujeres, puede aplicarse para reivindicar los derechos de las víctimas y como un control para buscar la no repetición de ignominias cotidianas, particularmente, del promedio de diez feminicidios registrados diariamente en México (ONCF, 2021), el feminicidio de Ingrid Escamilla, visibilizó la insuficiencia de la policía para atender la violencia de género en la Ciudad de México, en principio existe el precedente de que la víctima pidió ayuda múltiples veces a las autoridades competentes, sin éxito alguno, y después de su feminicidio numerosos medios de prensa publicaron las fotos de la escena del crimen y miles de usuarios de las redes sociales viralizaron (Redacción BBC, 2020).

En reacción a tan evidentes atropellos de la dignidad y derechos de la víctima, colectivos feministas usaron el hashtag \#IngridEscamilla, para publicar y compartir imágenes que evocaran calma, naturaleza y arte. Esto, con motivo de cambiar los algoritmos en internet y evitar que se siguieran difundiendo las fotografías del cri- 
men. En segundo lugar, para reivindicar la dignidad que había sido trastocada no sólo por su asesino, sino por los forenses que vendieron aquellas fotos a la prensa, así como a los periódicos que difundieron sus fotografías en sus medios. Por todo lo anterior, numerosos colectivos feministas protestaron y realizaron diversas acciones, la cuales desembocaron en la promulgación de la Ley Ingrid (2020), la cual sanciona la difusión de este tipo de contenido sensible o bien información de las víctimas de crímenes en la Ciudad de México (Signa Lab, 2020).

Por otro lado, en el sistema jurídico patriarcal tradicional, las mujeres padecen de un déficit de credibilidad al no ser consideradas como iguales en contraposición de sus compañeros varones por lo que ello les hace padecer una multiplicidad de injusticias hermenéuticas, que pueden ser resumidas como, aquellas injusticias donde un sujeto que está viviendo una suerte de violencia, no tiene las herramientas interpretativas para denunciar o incluso reconocer que está siendo vulnerada su dignidad (Fricker, 2007: 57). Esta relación entre los roles sociales y la moral crean estereotipos femeninos de género a través de los cuales se sanciona y se autorregula la conducta femenina transgresora de los valores establecidos por la colectividad (Álvarez, 2016: 5). De observar lo contrario a la expectativa social difundida hegemónica de las buenas mujeres, estas corren el riesgo de ser estigmatizadas (Goffman, 2006: 17). Esta distinción en la ley a partir del arquetipo de buenas y malas mujeres construye ficciones reglamentadoras de sexo y género en la sociedad y viceversa (Butler 2007). Si bien existe una añeja controversia entre derecho positivo y natural, donde el derecho positivo está ciego en materia de incondicionalidad de los fines, y el natural lo está igualmente respecto al condicionamiento de los medios (Benjamin, 1998: 25). Desde ambos derechos, queda evidenciado que la norma patriarcal limita a las mujeres a florecer en un sentido unidireccional. Entonces su desarrollo depende de la performatividad de una buena mujer para la ideología de género en la ley a la que se refiere Núñez.

Por su parte, Maclntyre sugiere que hay que identificar las características que son necesarias para que un individuo o una población concreta pueda florecer en uno u otro entorno, pero cuando un individuo o grupo florecen se dice algo más, ya que este se asemeja a otros conceptos que implican el concepto básico de bien (2001: 83). Ya que lo bueno para algunas personas, no necesariamente será bueno para otras, como el concepto de buena mujer y mala mujer. Ya que como se ha visto anteriormente, el ser "buenas mujeres" en un sentido legal y social de la palabra, no implica necesariamente que dicha característica sea positiva para los intereses de las propias mujeres. En palabras de Valcárcel, quien distingue que la defensa del mal es diferente al derecho al mal, por lo que "es necesario plantear si el mal se convierte en bien, por el mero uso de términos descriptivos, ya que la causa de la igualdad de los sexos ha sido defendida exteriormente acudiendo a términos utilitaristas, los que en el mejor de los sentidos claman que la liberación de las mujeres en consecuencia libera a los hombres de su tiranía, en este caso la vista reflejada en el derecho" (Valcárcel, 1994: 153-159).

Entonces ¿para quién es posible presentar al mal como un derecho?

Realizando un análisis histórico, partiendo desde 1791 hasta la actualidad, de 
las relaciones de género en el derecho y las olas feministas es importante contextualizar los cambios progresivos logrados por las reivindicaciones feministas, los significados de los cuerpos sexuados se producen en relación el uno con el otro, y cómo estos significados se despliegan y cambian con el tiempo ya que hay un énfasis necesario que debiese ponerse no en los roles asignados a las mujeres y a los hombres, sino a la construcción de la diferencia sexual en sí (Scott, 2011: 98). Al margen de esto, el feminismo como práctica de construcción de mundo (ZeriIli, 2008: 330), nos dice que la justicia no puede ni debe limitarse al ámbito jurídico.

Por ello es que incluso, remontándonos a referencias bíblicas, existe la posibilidad de que Eva fue castigada por la misoginia de Dios y Adán al consumir del fruto prohibido, castigándola por usar su propio albedrío marcando el inicio de la misoginia en la Biblia. Adicionalmente se ha señalado que el diablo en sus representaciones bíblicas, mas no folclóricas, ha sido representado como una mujer o en su defecto un ser intersexual. Por 10 que dichas representaciones e interpretaciones explicarían el trato desigual de las mujeres desde tiempos remotos. En principio por relacionarles con lo malo, como la desobediencia o el acceso al conocimiento 0 al poder, llamándolas brujas o herejes (Faxneld, 2017: 29).

Así pues, el transgredir un lugar que en apariencia no les es propio a las mujeres, trae un alto costo social, ya que al patriarcado le incomoda que las mujeres tengan acceso al poder; cuestionando el benévolo consejo dado a las mujeres de huir de lo que no les es propio. Lo anterior, en el entendido que lo propio de las mujeres es lo perteneciente al espacio privado, como el ámbito de los trabajos de cuidado, o aquellos espacios secundarios como en la historia o en la toma de decisiones. Entonces las mujeres no son consideradas sujetos y existen quienes animan desde aquella contracultura a seguir el camino de la sumisión disfrazándolo de terrenos de conquista (Valcárcel, 1994: 78). Entonces, los señalamientos como mala mujer o mala madre pueden tener una lógica binaria, donde atendiendo a diversos contextos, dichas acciones pueden constituir conductas reprobables o bien, paralelamente, imbricar un ejercicio de libertad y autonomía sobre sus vidas. Al respecto Foucault afirma que, entre los fines últimos de la justicia, se encuentran las libertades, y que dichas, nunca van a ser aseguradas por las instituciones y leyes (Focault, 1984: 245). Entonces la libertad es simplemente algo que se debe de ejercer. La única garantía de la libertad es la libertad misma (Arendt, 1993: 153). De lo anterior, puede afirmarse que el actuar como malas mujeres, conlleva a la liberación de dichas.

Aunado a lo anterior, Butler afirma que, en el momento en que la gente no puede confiar en la ley, la ley emancipa a la gente para crear su propio futuro político. Cuando la misma ley es un régimen violento, hay que oponerse a la ley, para paradójicamente oponerse a la violencia (Butler, 2015:23). Si entonces, la norma jurídica patriarcal es un ejercicio de violencia contra las mujeres, la cual crea una falsa dicotomía de dignidad y derechos entre varones y mujeres, bajo esta lógica que plantea la autora, estas quedan emancipadas de dichas normas, para así crear su propio futuro político, ya que la teoría-praxis feminista ha sido históricamente por excelencia una forma de rebeldía y desobediencia que ha liberado a las mujeres (Varela, 2020). 
Estas opresiones patriarcales por medio del sistema legal han sido ampliamente documentadas a través de la literatura por autoras feministas como Elena Poniatowska, quien en algunas de sus publicaciones, como en la herida de Paulina (2000), en la que describe las infamias a las que ha sido sometida una niña víctima de violación, y como es que todo el peso de la justicia patriarcal evita que ella pueda ejercer el derecho a decidir sobre su propio cuerpo en detrimento de sus deseos y circunstancias. $\mathrm{O}$ en la obra vienes de noche (2021) de la misma autora, en la que de narra la criminalización de la protagonista, a través de la justicia penal mexicana, y cómo es que, a pesar de que los sujetos aparentemente víctimas del delito de bigamia, realmente no estaban interesados en realizar alguna persecución jurídica contra la esposa que compartían todos estos. Sin embargo, el agente del Ministerio Público es quien persigue de forma inquisitiva a protagonista, la cual termina compurgando una pena de prisión por un delito que criminaliza a las malas mujeres, pero glorifica a los hombres desde las masculinidades tradicionales.

Siguiendo la literatura feminista mexicana, Rosario Castellanos también realiza importantes observaciones a las imposiciones en los roles de género de las buenas mujeres, tal como lo plasma en una de sus publicaciones más emblemáticas, en la cual refuta la paremia "mujer que sabe latín, ni tiene marido, ni tiene bien fin" en su obra con el mismo nombre, la autora realiza una frondosa crítica a las imposiciones sociales de género en distintos ámbitos de la vida tanto pública como privada en la cual, de esta obra se desprenden diversas configuraciones de las buenas mujeres que eufemísticamen- te, no son otra cosa más que procesos de control, sexuales, sociales y familiares engendrados desde lo más íntimo de la sociedad. Al margen de sus conclusiones, hace un llamado a las bondades de la educación para la liberación de las mujeres (Castellanos, 1973).

Una última consideración, es que existe una crítica al feminismo, desde la que se denuncia a este como una producción de mujeres del tercer mundo a partir de la mirada del subconjunto acotado de académicas que representan los feminismos del norte global. Ello además de delimitar el contenido semántico de los conceptos de las mujeres como la capacidad de definirse a ellas mismas, da como resultado la desigual distinción a través del discurso difundido y aceptado por las instituciones educativas, pues desde dicha perspectiva privilegiada, se ignoran otros contextos y necesidades (Mohanty, 2008: 1-4). Por su parte, existen colectividades que, aunque persigan los mismos fines que el feminismo no se identifican con dicho término. A manera de ejemplo se encuentran las Mujeres que luchan del Ejército Zapatista de Liberación Nacional (EZLN) en México, quienes desde sus trincheras buscan erradicar las opresiones extractivistas y patriarcales. También en esta categoría pueden ser consideradas las Mujeres Kurdas, quienes encabezan un movimiento activista por la paz en Siria, cuya finalidad es liberar a las mujeres de la esclavitud de ISIS. Por último, podemos considerar la Gulabi Gang de la India, que es un grupo de mujeres organizadas para concientizar a la sociedad sobre la violencia de género, erradicar el trabajo y matrimonio infantiles, promover el acceso a la educación de las mujeres, entre otros fines. 


\section{Conclusiones}

El feminismo es una teoría de la justicia que se actualiza por medio de la praxis de edificación colectiva, la cual nace desde una intuición reivindicativa de dignidad humana para las mujeres, que ha sido constituida a través de la lucha a través del tiempo y una multiplicidad de espacios, actividades que unívocamente han sido castigadas por las sociedades patriarcales.

La justicia feminista no puede ser encasillada ni reducida a un aparato burocrático de impartición de justicia, ya que ello implicaría crear justicia a partir de las leyes y tribunales que sistemáticamente han negado la dignidad femenina disidente.

Desde la academia nos hemos esmerado por construir teorías de la justicia a partir de un sustitucionalismo universalista desde espacios privilegiados. El feminismo ha sido una teoría de la justicia construida desde la perspectiva de las propias mujeres, en espacios descentralizados de los espacios privilegiados.

La dignidad y los derechos son construcciones sociales relacionales y no atributos biológicos, por lo que la aceptación y reconocimiento de ellos han sido adquiridos desde los diferentes espacios de lucha, entre ellas la feminista. Además, el feminismo ha sido tan dinámico que tiene una respuesta para cada tipo de mujer cuyos parámetros y demandas respondan a sus tiempos, ya que recordemos que los límites de lo legal y lo ilegal no son estáticos en el tiempo ni en las sociedades.

Todo testimonio de injusticia patriarcal debe ser abolido en orden de crear caminos de liberación. Es imperativo reconocer las nuevas formas de hacer justicia desde las voces de las personas oprimi- das, ya que las distintas ramas, luchas y escuelas feministas se han encargado de crear sus propias reglas, concepciones e intuiciones de justicia.

La justicia feminista no debe entenderse como el antónimo de justicia machista, ya que su naturaleza no es la violencia ni superioridad sobre los varones. Si bien, el feminismo es antagonista de las prácticas patriarcales, estamos partiendo de nuevas intuiciones de lo digno y lo justo, siempre incluyendo las experiencias de las mujeres.

La heteroaplicatividad de la norma patriarcal no reconoce los espacios correspondientes a los cuerpos no hegemónicos ya que dicha no ha sido pensada para cuerpos e identidades disidentes como los queer, intersexuales, trans, como destinatarios de la norma. No obstante, situándose la autora desde su personal perspectiva, aquellas luchas corresponden ser pugnadas desde las demandas de los cuerpos marginados por el derecho. A los sujetos adyacentes nos corresponde tomar un lugar solidario, empático y de escucha.

Frente al déficit de credibilidad femenina y la marginación en la justicia patriarcal surge una respuesta paralegal, lo cual justifica por qué las mujeres tienen el derecho a desobedecer las virtudes patriarcales a través del derecho a ser malas mujeres.

Si bien, no existe un modelo único y unívoco de mujer, tampoco existe un único modelo de feminismo por lo que debe hablarse de feminismos, ya que todos tienen como propósito adecuarse a mejorar la vida de las mismas mujeres en sus distintos contextos de interseccionalidad. Esta no universalización de la teoría feminista actualmente tiene debates abiertos que dialogan entre sí. Como, por ejemplo, si el 
sistema matriarcal de sociedad, economía y justicia, es capaz de frenar y revertir los daños realizados por el capitalismo y el patriarcado que han derivado en la actual crisis de sostenibilidad."

Existe una teoría de la justicia implícita en los feminismos. Existen tantas identidades y contextos en las formas de hacer justicia que por eso hay tantos tipos de feminismos. Por ello, ni el derecho ni el feminismo pueden justificar una teoría omnicomprensiva ni dogmática.

Si es posible construir las bases para una teoría de la justicia que no solo se quede en los textos ya que la misma praxis feminista ha construido sus propios caminos reivindicativos, primero como auto determinación de la categoría mujer, y después a los feminismos como construcción de sociedades más justas acorde a sus propios contextos.

Puede afirmarse que las leyes tienen que adaptarse a la composición y dignidad de las mujeres como destinatarias de estas y no viceversa.

Por su parte el feminismo ha sido una ficción no reglamentadora de las mujeres para las mujeres en su multidimensionalidad de posibilidades, asimismo, existe cada vez una mayor ramificación de concepciones feministas en búsqueda de espacios de divergencia y liberación. Los feminismos entonces le tienen que hacer justicia a una multiplicidad de mujeres afectadas por el patriarcado.

Esta no universalización de la teoría feminista actualmente tiene debates abiertos que continuamente dialogan entre sí.

Así pues, elaborar una teoría de la justicia desde los feminismos únicamente para aplicarse a los espacios jurisdiccionales y académicos es decidir sobre lo justo, lo bueno y lo digno para una multiplicidad de mujeres desde un espacio muy acotado e inaccesible para muchas de ellas. Esto corre el riesgo de segregar ciertas identidades al querer universalizar a una multiplicidad de sujetos en un solo discurso, un sincretismo injustificado.

\section{Bibliografía}

Álvarez, Nélida. (2016). "La moral, los roles, los estereotipos femeninos y la violencia simbólica". Revista humanidades. https://revistas.ucr.ac.cr/index.php/ humanidades/article/view/24964/25159 (consulta: 16/06/2021)

Arceo-Gómez, E. O., \& Campos-Vázquez, R. M. (2014). "Evolución de la brecha salarial de género en México". El trimestre económico, 81(323), 619-653.

Arendt, Hannah. (2018). La libertad de ser libres. Barcelona. Taurus.

Aparisi Miralles, A., \& Fernández Ruiz Gálvez, Encarnación. (2020). "Hacia un modelo de sexo-género de Igualdad en la diferencia". Anales de la Cátedra Francisco Suárez . 1-376. https://roderic.uv.es/handle/10550/58687 (consulta: 21/04/2021)

Bartra, Eli. (2012). "Acerca de la investigación y metodología feminista". En Epistemología, metodología y representaciones sociales. http://biblioteca.clacso.edu.ar/ Mexico/ceiich-unam/20170428032751/ pdf_1307.pdf (consulta: 12/04/2021)

Benjamin, Walter. (1998). Para una crítica de la violencia. Madrid. Taurus.

Blázquez, Norma. (2012). "Epistemología feminista: temas centrales, en Investigación feminista". Epistemología, metodología y representaciones sociales. En http:// 
biblioteca.clacso.edu.ar/Mexico/ceiichunam/20170428032751/pdf_1307.pdf (consulta: 12/04/2021)

Butler, Judith. (2007). El género en disputa: el feminismo y la subversión de la identidad. Barcelona. Paidós.

Butler, Judith. (2018). Resistencias. Repensar la vulnerabilidad y la repetición. México. Paradiso editores.

Camps, Victoria. (2020). "Derechos de la mujer y derechos universales". Contrastes: revista internacional de filosofía, ISSN 1136-4076, Vol. 25, N. 3, 2020, págs. 103-114. 10.24310/Contrastescontrastes. v25i3.11573 (consulta: 06/08/2021)

Carranco, Diana. (2020)."La no revictimización de las mujeres en México." Revista Digital Universitaria. https://www. revista. unam. mx/2020v21n4/la_no_revictimizacion_de_las_mujeres_en_ mexico (consulta: 09/04/2021)

Castellanos, Rosario. (2003). Mujer que sabe latín... México. Fondo de cultura económica.

Costa, Malena. (2017), "Feminismos jurídicos en Argentina" en Paola Bergallo y Aluminé Moreno (coords.), Hacia políticas judiciales de género (pp. 237-260). Buenos Aires: Jusbaires Editorial. https:// ri.conicet.gov.ar/handle/11336/108412 (consulta: 27/06/2021)

De Barbieri, Teresita. (1993). "Sobre la categoría género: una introducción teórico-metodológica". Debates en sociología, (18), 145-169. http://revistas.pucp.edu. pe/index.php/debatesensociologia/article/ view/6680/6784 (consulta: 05/10/2021)

De Beauvoir, Simone. (1981). El segundo sexo. Buenos Aires: Siglo XX. https:// www.segobver.gob.mx/genero/docs/Biblioteca/El_segundo_sexo.pdf (consulta: 08/09/2021)
DEM. (2021). Diccionario del Español de México. https://dem.colmex.mx/Ver/ teor\%c3\%ada (consulta: 09/04/2021)

Deschamps, Joelle. (2020). Yo paro porque puedo. Oxfam México. https://www. oxfammexico.org/justicia_genero (consulta: 08/08/2021)

Eichler, Margrit. (1997). "Feminist methodology". Current sociology, 45(2), 9-36. https:// doi.org/10.1177/001139297045002003 (consulta: 02/02/2021)

Eyer, Kate. (2011). "That's Not Discrimination: American Beliefs and the Limits of Anti-Discrimination Law". Minnesota Law Review 96, 1275. https://heinonline.org/HOL/Page?handle=hein.journals/mnlr96\&div=34\&g_sent $=1 \&$ casa token=V03I_dUYEREAAAAA:EqG8QBp uUhmPUgDIx2LP1tfVd20LF03Zk_tfvnrfeZ_B-55COyHzpuPwGAtmsj7EwmOu QiUQg\&collection=journals (consulta: 26/05/2021)

Faxneld, Per. (2017). Satanic feminism: Lucifer as the liberator of woman in nineteenth-century culture. Nueva York. Oxford University Press.

Federici, Silvia. (2013). El patriarcado del salario. Críticas feministas al marxismo. https://www.tintalimon.com.ar/public/6u 3i8er7ws89tb3b9via6ulahhx8/El\%20patriarcado\%20del\%20salario.pdf (consulta: $26 / 05 / 2021$ )

Fraser, Nancy. (1996). "Redistribución y reconocimiento hacia una visión integrada de justicia del género". Revista internacional de filosofía política. http:/le-spacio. uned.es/fez/eserv/

bibliuned:filopoli-1996-8 - 822568E8 D 884 - B C 64-274D-3C464F9C410B/ redistribucion_reconoci-miento.pdf (consulta: 12/02/2021) 
Foucault, Michael. (1984). The Foucault reader. Nueva York. Pantheon.

Fricker, Miranda. (2007). Epistemic injustice: Power and the ethics of knowing. México. Nueva York: Oxford University Press.

Goffman, Erving. (2006). Estigma. La identidad deteriorada. Buenos Aires: Amurrutu Editores.

Harding, Sandra. (1998). “¿Existe un método feminista?" Debates en torno a una metodología feminista, 2, 9-34. https:// biblioteca.colson.edu.mx/e-docs/RED/ Debates_en_torno_a_una_metodologiaEl_Bartra.pdf (consulta: 22/02/2021)

Horbath, J. E., \& Gracia, A. (2014). "Discriminación laboral y vulnerabilidad de las mujeres frente a la crisis mundial en México". Economía, sociedad y territorio, 14(45), 465-495. http://www.scielo. org. $m x /$ scielo.php?script=sci_arttext\&pid $=$ S1405-84212014000200006 (consulta: 09/04/2021)

Lagarde, Marcela. (2016). Los cautiverios de las mujeres: madresposas, monjas, putas, presas y locas. México. Siglo XXI Editores.

Maclntyre, Alsadir. (2001). Animales racionales y dependientes: por qué los seres humanos necesitamos las virtudes. Barcelona. Paidos.

MacKinnon, Catharinne (2007). Women's lives, men's laws. Cambridge, Massachusetts. Harvard University Press.

Mohanty, Chandra. (2008). "Bajo los ojos de occidente. Academia Feminista y discurso colonial". Descolonizando el feminismo: teorías y prácticas desde los márgenes, 112-161. http://ibdigital.uib.es/greenstone/collect/cd2/index/assoc/caib0094.dir/ caib0094.pdf (consulta: 31/05/2021)
Núñez, Lucía. (2021). El género en la ley penal: crítica feminista de la ilusión punitiva. México. Universidad Nacional Autónoma de México.

Nussbaum, Martha. (2014). Emociones políticas. Barcelona. Paidós.

OCNF. (2021). Observatorio Ciudadano Nacional contra el Feminicidio. https:// www.observatoriofeminicidiomexico.org/ (consulta: 09/04/2021)

ONU. (1948). Declaración universal de los derechos humanos. https://www. un.org/es/about-us/universal-declarationof-human-rights (consulta: 27/07/2021)

Poniatowska, Elena. (2021). De noche vienes. México. Fondo de cultura económica.

Poniatowska, Elena. (2000). La herida de Paulina. México. Fondo de cultura económica.

Putnam, Ruth Ann. (1995). "Why not a feminist theory of justice?". In Nussbaum, M. C., \& Glover, J. (Eds.). (1995). Women, culture, and development: A study of human capabilities. pp. 298-331. . Nueva York. Oxford University Press.

Redacción BBC. (2020 febrero 11). Feminicidio de Ingrid Escamilla: la indignación en México por el brutal asesinato de la joven y la difusión de las fotos de su cadáver. BBC mundo. https://www. bbc.com/mundo/noticias-america-latina-51469528 (consulta: 09/03/2021)

Reinserta. (2020). Diagnóstico sobre la percepción del desempeño de la defensoría penal en México. https://reinserta.org/ wp-content/uploads/2020/10/diagnosticosobrelapercepciondeldesempenodeladefensoriapenalenmexico.pdf (consulta: 09/04/2021)

Rubin, Gayle. (1975). "The traffic in women: Notes on the" political econ- 
omy" of sex". Deviations. Duke University Press. Nueva York. https://doi. org/10.1515/9780822394068-003 (consulta: 01/03/2021)

Rubio, Ana y Bodelón, Encarna. (2013). "Lenguaje jurídico y género: sobre el sexismo en el lenguaje jurídico". Consejo general del Poder Judicial. http://www. upv.es/entidades/VRSC/info/U0711345. pdf (consulta: 26/05/2021)

Salamanca, Antonio. (2017). "El fetiche jurídico del capital: Expansión imperialista de su hegemonía sistémica a través de los estudios de derecho". Problemata: Revista Internacional de Filosofía, vol. 8, no 1, p. 324-402. (consulta: 11/05/2021)

Sarrió, M., Barberá, E., Ramos, A., \& Candela, C. (2002). El techo de cristal en la promoción profesional de las mujeres. Revista de psicología social, 17(2), 167-182. https:// doi.org/10.1174/021347402320007582 (consulta: 16/04/2021)

Schiebinger, Londa. (2004). ¿Tiene sexo la mente?: las mujeres en los orígenes de la ciencia moderna. Valencia. Universitat de València.

Signa Lab. (2020). Ingrid Escamilla: apagar el horror. https://abiertodediseno.mx/ expo_central/signa_lab-laboratorio-deinnovacion-tecnologica-y-de-estudios-interdisciplinarios-aplicados-del-iteso/ (consulta: 11/05/2021)

Scott, Joan. (2011). "Género: ¿Todavía una categoría útil para el análisis?". Teoría y pensamiento feminista. https://repositorio.unal.edu.co/handle/unal/53777 (consulta: 31/05/2021)

SCJN. (2020). Protocolo para juzgar con perspectiva de género. Suprema Corte de Justicia de la Nación. https:// www.scjn.gob.mx/derechos-humanos/ sites/default/files/protocolos/archivos/2020-11/Protocolo\%20para\%20juzgar $\% 20$ con\%20perspectiva\%20de\%20 g\%C3\%A9nero\%20\%28191120\%29.pdf (consulta: 16/08/2021)

Varela, Nuria. (2014). Feminismo para principiantes. B de books. https://kolectivoporoto.cl/wp-content/uploads/2015/11/ Varela-Nuria-Feminismo-Para-Principiantes.pdf (consulta: 19/05/2021)

Varela, Nuria. (2020). El tsunami feminista. Barcelona. Ediciones B.

Valcárcel, Amelia., Valcárcel, A., \& de Quirós, B. (1994). "Sexo y filosofía: Sobre" mujer" y" poder"" (No. 14). Anthropos Editorial. Barcelona.

Vela, Estefanía. (2017). La discriminación en el empleo en México. Senado de México. http://bibliodigitalibd.senado. gob.mx/handle/123456789/3854 (consulta: 12/04/2021)

WLW. (2021). Womens Link Worldwide. Premios género y justicia al descubierto. https://www. womenslinkworldwide.org/ premios (consulta: 21/09/2021)

WLW. (2016). ¿Cerró bien las piernas?. Ganador del premio garrote de plata. https://www.womenslinkworldwide.org/ premios/casos/cerro-bien-las-piernas. (consulta: 21/09/2021)

WLW. (2016). Violada por accidente. Ganador del premio garrote de plata. https:// www.womenslinkworldwide.org/premios/ casos/violada-por-accidente. (consulta: 21/09/2021)

WLW. (2012). Caso GulNaz D/o Abdul Ahad. Ganador del premio garrote de plata. https://www.womenslinkworldwide.org/ premios/casos/caso-gulnaz-d-o-abdulahad. (consulta: 21/09/2021) 
WLW. (2010). Sentencia T-622/2010. Ganador del premio garrote de plata. https:// www.womenslinkworldwide.org/premios/ casos/sentencia-t-622-2010. (consulta: 21/09/2021)

WLW. (2010). Caso Ávalos Francisco Domingo. Ganador del premio garrote de plata. https://www.womenslinkworldwide. org/premios/casos/caso-avalos-franciscodomingo. (consulta: 21/09/2021)

WLW. (2010). Jurisdicción Primera Criminal y de Menores de Sete Lagoas. Ganador del premio garrote de plata. https:// www.womenslinkworldwide.org/premios/ casos/jurisdiccion-primera-criminal-yde-menores-de-sete-lagoas. (consulta: 21/09/2021)

Zerilli, Linda., \& Arijón, T. (2008). El feminismo y el abismo de la libertad. México. Fondo de Cultura Económica. 